\title{
28. ANISOTROPY OF BASALTS, HOLE 462A, NAURU BASIN, DEEP SEA DRILLING PROJECT LEG 891
}

\author{
Naoyuki Fujii, Department of Earth Sciences, Kobe University, Japan \\ and \\ Yozo Hamano, Earthquake Research Institute, University of Tokyo, Japan ${ }^{2}$
}

\begin{abstract}
Measurements of the anisotropy of magnetic susceptibility (AMS) in basalts cored from 1070 to $1209 \mathrm{~m}$ sub-bottom depth in Hole $462 \mathrm{~A}$ reveal that samples with a high ratio of maximum (K1) to minimum (K3) principal susceptibility show a prolate type of anisotropy in which $\mathrm{K} 1$ axes are nearly vertical. For other prolate types, $\mathrm{K} 1$ axes vary widely. Although the oblate type of AMS is less common among these basalts, K3 axes are nearly vertical in the upper units and horizontal in the lower units. The anisotropy of compressional wave velocities measured for the same specimen shows no correlation with the degree and type of AMS. This finding indicates that AMS could have been caused by variations in flows but not by compressive stress. Processes of emplacement of basaltic sills and flows must have been complex, because directions of principal axes of AMS vary from unit to unit.
\end{abstract}

\section{INTRODUCTION}

Basalts cored from Hole $462 \mathrm{~A}$ occur in sills and flows produced during Early to middle Cretaceous midplate volcanism and erupted onto oceanic basement about $150 \mathrm{Ma}$ (Larson, Schlanger, et al., 1981). Questions remain about the processes of eruption or emplacement of such a basin-fill, sill-flow complex during midplate volcanism (Schlanger et al., 1981).

The anisotropy of magnetic susceptibility (AMS) of igneous and metamorphic rocks could be caused by the preferred orientation of nonequant grain shape (shape anisotropy), linear or planar alignment of grains (textural anisotropy), and crystallographic directions of intrinsically anisotropic magnetic minerals (magnetocrystalline anisotropy) (e.g., Uyeda et al., 1963; Birch, 1979). The former two mechanisms would be attributed to the cause of AMS in basalts (Khan, 1962; Ellwood and Watkins, 1976) and the last mechanism might be probable in metamorphosed plutonic rocks (Birch, 1979).

If the grain shape deviates from spherical, the shape anisotropy would dominate in basaltic sills and flows. Laminar flows generally produce preferred orientations of spheroidal grains with longer axes normal to both flow velocity and its maximum gradients for prolate particles and with short axes normal to streamlines for oblate particles (e.g., Happel and Brenner, 1965). In addition, emplacement modes of basalts in the oceanic crust can be distinguished by using AMS measurements (Ellwood, 1975).

It is possible that the observed anisotropy in other physical properties such as elastic wave velocities could be related to AMS caused by anisotropic alignment of

\footnotetext{
${ }^{1}$ Moberly, R., Schlanger, S. O., et al., Init. Repts. DSDP, 89: Washington (U.S. Govt. Printing Office).

2 Addresses: (Fujii) Department of Earth Sciences, Kobe University, Nada, Kobe 657 , Japan; (Hamano) Earthquake Research Institute, University of Tokyo, Bunkyo-ku, Tokyo 113, Japan.
}

spheroidal grains and pores. For this reason, we report AMS and the anisotropy of compressional wave velocities for basalts from Hole 462A, Leg 89 .

\section{METHODS}

All the samples studied were minicores 1.5 to $2.2 \mathrm{~cm}$ long and $2.5 \mathrm{~cm}$ in diameter. Compressional wave velocities and wet-bulk density were measured on board ship. The same specimens were then used for magnetic analysis including NRM and AF demagnetization. Magnetic susceptibility measurements for three mutually perpendicular directions were made aboard ship after AF demagnetization by using a Bison Model 3101 susceptibility bridge (Site 462 report, this volume). However, this measurement gave only apparent AMS. In order to obtain principal components of a magnetic susceptibility ellipsoid, a 6-spin measurement was performed by using a Shonstedt SSM-1A spinner magnetometer (Noltimier, 1971). Because five independent components of magnetic susceptibility tensor were obtained, an absolute value for one of the three diagonal components was measured by using a Bison susceptibility bridge. After correcting for the effects of induced demagnetization, three principal components of intrinsic magnetic susceptibility and their orientations to the vertical axis were calculated. The accuracy and reproducibility were within a few percentage points. The description of this measurement has been given in more detail by Hamano and Yomogida (1982).

\section{RESULTS}

Results are presented in Table 1 , in which $\langle\mathrm{K}\rangle$ is the mean susceptibility defined by $\langle\mathrm{K}\rangle^{-1}=\left(\mathrm{K}^{-1}+\right.$ $\left.\mathrm{K} 2^{-1}+\mathrm{K} 3^{-1}\right) / 3$, and $\mathrm{K} 1, \mathrm{~K} 2$, and $\mathrm{K} 3$ are the maximum, intermediate, and minimum susceptibilities, respectively. Values of $\langle K\rangle$ are in $1400-2700 \times 10^{-6}$ cgs-emu range. The small variation in $\langle\mathrm{K}\rangle$ is probably the result of the narrow grain size variation and relatively homogeneous chemical composition of the samples. The ratio $\mathrm{K} 1 / \mathrm{K} 3$ is commonly used as a measure of the degree of anisotropy, and varies from 1.025 \pm 0.002 to $1.285 \pm 0.002$. Among all the samples studied (25), this ratio is greater than 1.1 in only four samples.

In order to describe the types of anisotropy observed, a parameter, $A$, defined by $\tan ^{2} A=(\mathrm{K} 2-\mathrm{K} 3) /(\mathrm{K} 1-$ $\mathrm{K} 2$ ), is introduced (Hamano and Yomogida, 1982). When the susceptibility ellipsoid is prolate, the value of $A$ falls 
Table 1. Anisotropy of magnetic susceptibility of basalts, Hole $462 \mathrm{~A}$.

\begin{tabular}{|c|c|c|c|c|c|c|c|c|}
\hline $\begin{array}{l}\text { Sample } \\
\text { (hole-core-section } \\
\text { interval } \mathrm{cm} \text { level) }\end{array}$ & $\begin{array}{l}\text { Sub-bottom } \\
\text { depth } \\
\text { (m) }\end{array}$ & 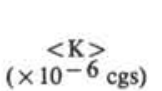 & $\mathrm{K} 1 / \mathrm{K} 3$ & $\begin{array}{l}A \\
\left({ }^{\circ}\right)\end{array}$ & $F$ & $\underset{\left({ }^{\circ}\right)}{|\theta|^{a}}$ & $\frac{V_{\text {max }}{ }^{b}}{V \text { min }}$ & $\begin{array}{c}\text { Volcanic } \\
\text { unit }\end{array}$ \\
\hline $462 A-93-1,64$ & 1072.3 & 2288 & 1.064 & 40.0 & 1.050 & 86.0 & 1.024 & 45 \\
\hline $462 A-93-2,76$ & 1074.0 & 2288 & 1.034 & 29.1 & 1.029 & 21.6 & 1.028 & 45 \\
\hline $462 A-94-3,39$ & 1080.0 & 2347 & 1.063 & 55.6 & 1.041 & (6.1) & 1.031 & 45 \\
\hline $462 A-94-6,140$ & 1085.5 & 2054 & 1.028 & 36.3 & 1.023 & 75.6 & 1.023 & 45 \\
\hline $462 \mathrm{~A}-95-1,84$ & 1086.5 & 2160 & 1.047 & 17.5 & 1.045 & 80.8 & 1.015 & 45 \\
\hline $462 A-96-1,57$ & 1095.5 & 1937 & 1.204 & 37.4 & 1.161 & 14.2 & 1.005 & 46 \\
\hline $462 \mathrm{~A}-96-4,14$ & 1099.5 & 2103 & 1.048 & 73.3 & 1.026 & $(7.8)$ & 1.051 & 46 \\
\hline $462 \mathrm{~A}-97-1,101$ & 1105.0 & 1378 & 1.056 & 28.4 & 1.049 & 86.9 & 1.093 & 46 \\
\hline $462 \mathrm{~A}-97-3,99$ & 1108.0 & 2265 & 1.027 & 38.3 & 1.043 & 53.1 & 1.028 & 46 \\
\hline $462 A-98-1,79$ & 1114.0 & 1871 & 1.083 & 42.5 & 1.130 & 11.7 & 1.026 & 46 \\
\hline $462 A-98-5,74$ & 1120.1 & 1951 & 1.033 & 57.0 & 1.021 & $(5.4)$ & 1.025 & 46 \\
\hline $462 A-99-1,51$ & 1122.8 & 2248 & 1.026 & 58.0 & 1.017 & $(1.8)$ & 1.027 & 46 \\
\hline $462 \mathrm{~A}-100-1,136$ & 1132.9 & 2236 & 1.025 & 38.2 & 1.040 & 83.3 & 1.053 & 48 \\
\hline $462 \mathrm{~A}-100-3,49$ & 1135.0 & 1663 & 1.030 & 39.2 & 1.024 & 44.4 & 1.009 & 48 \\
\hline $462 \mathrm{~A}-101-1,91$ & 1135.4 & 1828 & 1.027 & 8.2 & 1.026 & 85.0 & 1.013 & 48 \\
\hline $462 A-101-4,67$ & 1139.7 & 2462 & 1.056 & 51.2 & 1.038 & (86.4) & 1.015 & 48 \\
\hline $462 \mathrm{~A}-102-2,73$ & 1145.1 & 2394 & 1.285 & 23.2 & 1.258 & 3.2 & 1.037 & 48 \\
\hline $462 \mathrm{~A}-103-1,107$ & 1153.1 & 1773 & 1.036 & 48.2 & 1.026 & $(85.0)$ & 1.023 & 50 \\
\hline $462 \mathrm{~A}-104-1,106$ & 1162.3 & 1669 & 1.041 & 25.9 & 1.037 & 59.9 & 1.018 & 51 \\
\hline $462 \mathrm{~A}-105-1,15$ & 1170.5 & 2083 & 1.050 & 19.2 & 1.047 & 82.8 & 1.025 & 52 \\
\hline $462 \mathrm{~A}-105-3,47$ & 1173.7 & 2697 & 1.128 & 30.9 & 1.109 & 6.3 & 1.074 & 52 \\
\hline $462 \mathrm{~A}-106-1,55$ & 1174.8 & 2627 & 1.031 & 61.5 & 1.019 & (29.2) & 1.034 & 52 \\
\hline $462 \mathrm{~A}-106-2,123$ & 1177.0 & 2245 & 1.026 & 48.0 & 1.019 & (89.4) & 1.025 & 52 \\
\hline $462 \mathrm{~A}-108-1,77$ & 1190.3 & 2444 & 1.129 & 23.0 & 1.118 & 11.8 & 1.020 & 52 \\
\hline $462 A-109-2,86$ & 1201.6 & 2490 & 1.024 & 28.0 & 1.021 & 22.8 & 1.010 & 55 \\
\hline
\end{tabular}

between $0^{\circ}$ and $45^{\circ}$. When it is oblate, $A$ varies from $45^{\circ}$ to $90^{\circ}$. The angle $|\Theta|$ between the vertical axis and $\mathrm{K} 1$ (for prolate) or K3 (for oblate) is listed to show the alignment of the shape anisotropy of magnetic grains. Prolate samples with higher $\mathrm{K} 1 / \mathrm{K} 3$ ratios than 1.08 show that $|\Theta|$ is less than $15^{\circ}$. Four oblate samples from volcanic units 45 and 46 indicate that the $\mathrm{K} 3$ axis coincides with the vertical axis within $10^{\circ}$. However, in volcanic units 48,50 , and $52, \mathrm{~K} 3$ axes of oblate samples are nearly parallel to the horizontal plane, with the exception of one sample (462A-106-1, $55 \mathrm{~cm}$ ) (Table 1).

From the measurements of the compressional wave velocities for vertical (subscript v) and horizontal (subscripts h1 and h2) directions, including one (h1) along the minicore axis, the apparent anisotropy defined by $\mathrm{A}(\mathrm{V})=3\left(\mathrm{~V}_{\mathrm{h} 1}+\mathrm{V}_{\mathrm{h} 2}-2 \mathrm{~V}_{\mathrm{v}}\right) / 2\left(\mathrm{~V}_{\mathrm{h} 1}+\mathrm{V}_{\mathrm{h} 2}+\mathrm{V}_{\mathrm{v}}\right) \times 100$, varies from -4.3 to $5.5 \%$ (Site 462 report, this volume). In order to demonstrate the variation of velocities in three directions, the ratio of maximum to minimum compressional wave velocities $\mathrm{V}_{\max } / \mathrm{V}_{\min }$ is listed in Table 1 . $\mathrm{A}(\mathrm{V})$ and $\mathrm{V}_{\max } / \mathrm{V}_{\min }$ show little correlation with either the degree or type of AMS.

\section{DISCUSSIONS AND CONCLUSIONS}

In Figure 1 the ratio $\mathrm{K} 1 / \mathrm{K} 3$ and the anisotropic type parameter $A$ of AMS and the apparent anisotropy $\mathrm{A}(\mathrm{V})$ and the ratio $\mathrm{V}_{\max } / \mathrm{V}_{\min }$ of the compressional wave velocities are plotted against sub-bottom depth. The samples with higher $\mathrm{K} 1 / \mathrm{K} 3$ values than 1.1 seem to lie near the upper and lower boundaries of each volcanic unit. This would be consistent with the idea that these volcanic units are sills, if the higher degree of AMS would reflect the higher shear stress or higher concentration of streamlines during the emplacement of each volcanic unit. However, prolate and oblate types of AMS seem to indicate no relation to location in the volcanic units.

$\mathrm{A}(\mathrm{V})$ apparently decreases with depth, and the velocity in the vertical direction becomes higher than that in the horizontal direction [i.e., the value of $A(V)$ is less than zero] below volcanic unit 48 . As compressional wave velocities were measured under one atmosphere and in a seawater-saturated condition, the error in $\mathrm{A}(\mathrm{V})$ was probably at most a few percentage points. The decrease of $A(V)$ with depth could be caused by the gradual change in the orientation distribution of microcracks and pores (with little effect upon AMS), though microscopic observations showed no apparent directional differences.

In order to distinguish the emplacement mode of basalts, a parameter $F$, defined by $F^{2}=\mathrm{K} 1{ }^{2} /(\mathrm{K} 2 \cdot \mathrm{K} 3)$, has been used and a value of $F=1.04$ separates intrusives from extrusives with $80 \%$ confidence (Ellwood, 1975). About $56 \%$ of the samples studied show extrusives $(F<1.04)$, in which extrusives and intrusives distribute randomly in each volcanic unit (Table 1), so that this criterion seems inapplicable to the basalts in this study. It may be that this criterion seems inapplicable because it has been applied to relatively younger (and less altered) basalts (Ellwood, 1978). Further magnetic analyses are needed to clarify the effects of alteration and oxidation processes on recrystallization and reorientation of magnetic grains.

The ellipsoid shape of magnetic susceptibility in basalts represents the preferred alignment of grains because of the recrystallization and deformation in a stress field, or the rotation of grains in partially crystallized flows (e.g., Khan, 1962; Ellwood, 1978; Birch, 1979). In discussing the preferred orientation of the ellipsoid shape of AMS, it should be noted that larger values of $\mathrm{K} 1 / \mathrm{K} 3$ 


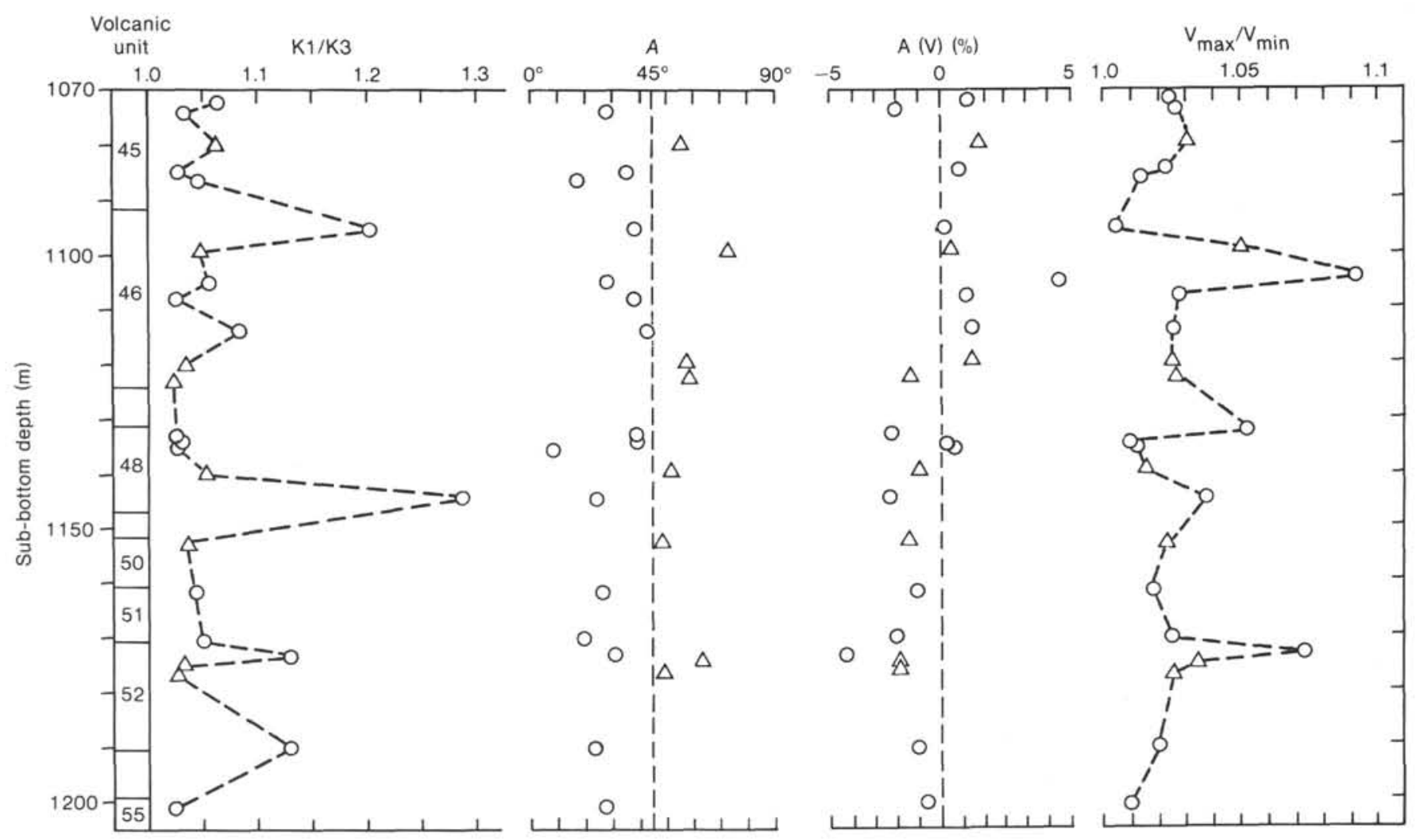

Figure 1. The ratio $\mathrm{K} 1 / \mathrm{K} 3$ and the anisotropic type parameter $A$ of $\mathrm{AMS}$ and the apparent anisotropy $\mathrm{A}(\mathrm{V})$ and the ratio $\mathrm{V}_{\max } / \mathrm{V}_{\min }$ of the compressional wave velocities versus sub-bottom depth. Open circles and triangles indicate prolate and oblate types of AMS, respectively. See text for further explanations.

result in less uncertainty in the directions of principal components. Samples with a higher degree of AMS (i.e., higher values of $\mathrm{K} 1 / \mathrm{K} 3$ than 1.08 ) show only the prolate type in volcanic units 46,48 , and 52 (Fig. $2 \mathrm{~A}$ ), and their $\mathrm{K} 1$ axes are nearly vertical within $15^{\circ}$ (Table 1$)$. It is noteworthy that samples with an oblate (foliation) type of AMS in volcanic units 45 and 46 show small values of $|\theta|$, whereas values of $|\theta|$ are nearly $90^{\circ}$ for units below 48. If laminar flows of basalts during their emplacement would produce the preferred orientation of spheroidal particles (Khan, 1962; Happel and Brenner, 1965), these observations might suggest horizontal flow in unit 46 and a vertical flow in unit 52, and complex flows in other units.

If applied stress would deform grains and pores, the alignment of magnetic grains should correlate with them and reflect the anisotropy of elastic properties. For example, uniaxial compression should produce an oblate (foliation) type of anisotropy, as suggested by Hamano and Yomogida (1982) and Fujii et al. (1983). There seems to be little correlation between the ratio $\mathrm{K} 1 / \mathrm{K} 3$ and the anisotropic type parameter $A$ (Fig. $2 \mathrm{~A}$ ), or the ratio $\mathrm{V}_{\max } /$ $\mathrm{V}_{\min }$ (Fig. 2B). In addition, samples with an oblate type of AMS were observed less than samples with a prolate type of AMS, which suggests that the deformation of grains resulting from applied stress does not significantly contribute to the origin of AMS in basalts studied.

Although the number of samples we studied is small, we can make some observations: (1) Values of magnetic susceptibilities fall in a narrow range indicating homo- geneous grain size, pore or crack size distribution, and chemical compositions. (2) Samples with higher K1/K3 values show the prolate type of AMS, in which case K1 axes are nearly vertical in volcanic units 46,48 , and 52 (see Site 462 report for description of Hole $462 \mathrm{~A}$ volcanic units). (3) Samples with an oblate type of AMS, though they are less frequent, show nearly vertical K3 axes in volcanic units 45 and 46 , whereas those in units 48,50 , and 52 show nearly horizontal $\mathrm{K} 3$ axes. (4) There seems to be no correlation between the degree and type of AMS and the anisotropy of compressional wave velocities.

These observations seem to be consistent with the idea that basalts in the lowest part of Hole $462 \mathrm{~A}$ are related to a sill-flow complex. However, it is difficult to interpret the nature of emplacement from the observed distribution of AMS. It appears that eruption or emplacement processes of the basin-fill basalts was of mixed mode, resulting in nonsystematic complex distributions of AMS as well as the anisotropy of compressional wave velocities.

\section{ACKNOWLEDGMENTS}

One of the authors (NF) thanks R. Moberly, S. Schlanger (CoChief Scientists), and colleagues of Leg 89 for their kind suggestions and encouragement. Discussions with J. Ogg were especially helpful for shipboard magnetic susceptibility measurements. Critical comments and suggestions by M. Manghnani and M. Salisbury contributed greatly to the revision of the original manuscript. This work was partly supported by the Japanese IPOD Committee and a grant from the Ministry of Education, Science, and Culture, Japan. We are grateful to Mmes H. Wada and J. Asakura for typing the manuscript. 
A

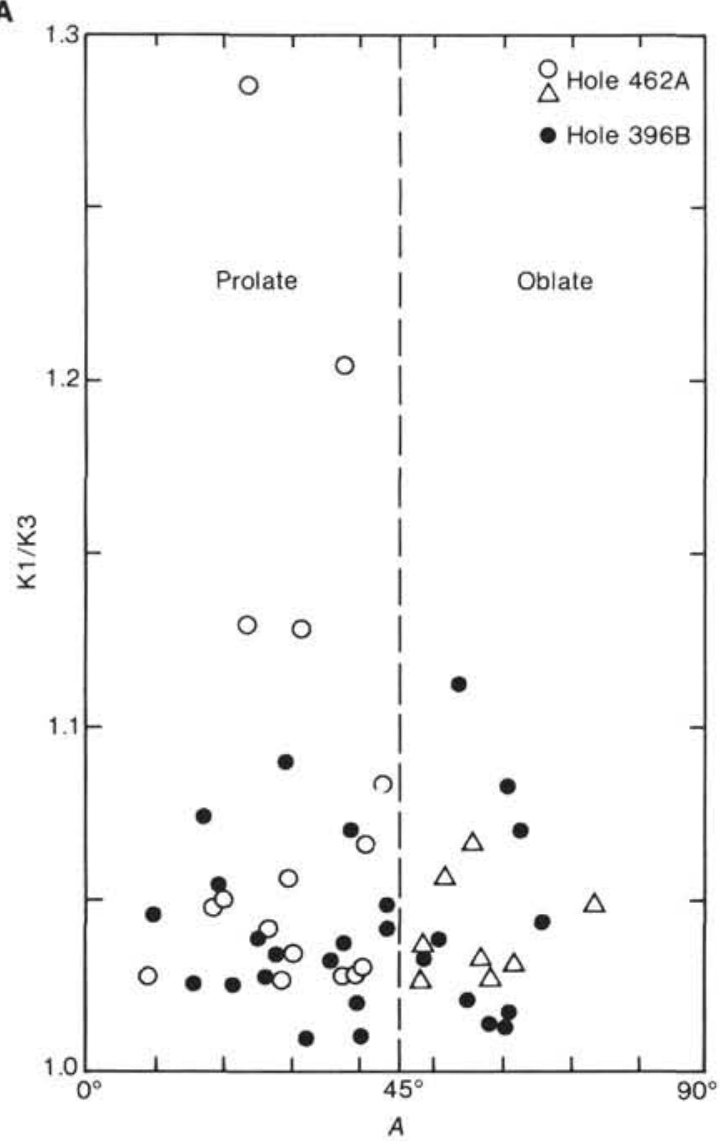

B

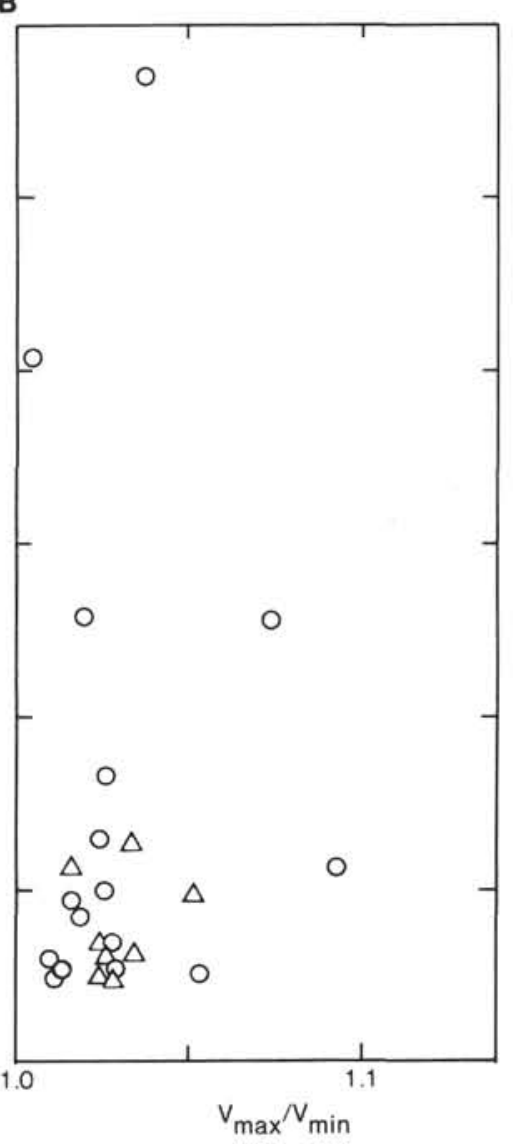

Figure 2. A. The ratio K1/K3 versus parameter $A$ for basalts from Hole $462 \mathrm{~A}$ (this chapter) and from Hole 396B (Ellwood and Watkins, 1978). B. The ratio $\mathrm{K} 1 / \mathrm{K} 3$ versus $\mathrm{V}_{\max } / \mathrm{V}_{\min }$ for Hole $462 \mathrm{~A}$ basalts.

\section{REFERENCES}

Birch, F. S., 1979. Magnetic fabric of the Exeter Pluton, New Hampshire. J. Geophys. Res., 84:1129-1137.

Ellwood, B. B., 1975. Analysis of emplacement mode in basalt from Deep-Sea Drilling Project Holes 319A and 321 using anisotropy of magnetic susceptibility. J. Geophys. Res., 80:4805-4808.

1978. Flow and emplacement direction determined for selected basaltic bodies using magnetic susceptibility anisotropy measurements. Earth Planet. Sci. Lett., 41:254-264.

Ellwood, B. B., and Watkins, N. D., 1976. Comparison of observed intrusive to extrusive ratios in Iceland and the Troodos Massif with results of experimental emplacement mode analysis of DSDP igneous rocks. J. Geophys. Res., 84:4152-4156.

1978. Experimental emplacement mode determination of basalt in Hole 396B. In Dmitriev, L., Heirtzler, J., et al., Init. Repts. DSDP, 46: Washington (U.S. Govt. Printing Office), 363-367.

Fujii, N., Ito, K., Miyamoto, M., and Hamano, Y., 1983. Shape of $\mathrm{Fe}-\mathrm{Ni}$ grains and magnetic susceptibility anisotropy in Antarctic chondrites. Mem. Nat. Inst. Polar Res., Spec. Issue, 30:389-402.
Hamano, Y., and Yomogida, K., 1982. Magnetic anisotropy and porosity of Antarctic chondrites. Mem. Nat. Inst. Polar Res., Spec. Issue, 25:281-290.

Happel, J., and Brenner, H., 1965. Low Reynolds Number Hydrodynamics: Englewood Cliffs, N.J. (Prentice Hall).

Khan, M. A., 1962. The anisotropy of magnetic susceptibility of some igneous and metamorphic rocks. J. Geophys. Res., 67:2873-2885.

Larson, R. L., Schlanger, S. O., et al., 1981. Init. Repts. DSDP, 61: Washington (U.S. Govt. Printing Office).

Noltimier, H. C., 1971. Determining magnetic anisotropy of rocks with a spinner magnetometer giving in-phase and quadrature data output. J. Geophys. Res., 76:4849-4854.

Schlanger, S. O., Jenkyns, H. C., and Premoli Silva, I., 1981. Volcanism and vertical tectonics in the Pacific Basin related to global Cretaceous transgressions. Earth Planet. Sci. Lett., 52:435-449.

Uyeda, S., Fuller, M. D., Belshe, J. C., and Girdler, R. W., 1963. Anisotropy of magnetic susceptibility of rocks and minerals. J. Geophys. Res., 68:279-291.

Date of Initial Receipt: 13 July 1984

Date of Acceptance: 19 October 1984 